\title{
O.D.E.S. : An Online Dynamic Examination System based on a CMS Wordpress plugin
}

\author{
George F. Fragulis*, Lazaros Lazaridis*, \\ Maria Papatsimouli* and Ioannis A. Skordas* \\ * Laboratory of Web Technologies \& Applied Control Systems \\ Dept. Of Electrical Engineering \\ Western Macedonia Univ. of Applied Sciences, Kozani, Hellas
}

\begin{abstract}
This paper describes the online dynamic examination application plugin named "ODES", developed according to the open source software philosophy, where the CMS Wordpress is used as programmers/coders are given the potential to develop applications from scratch with safety and ease. In ODES application there exists two types of users: admin/teacher and student. The admin/teacher can create/edit/delete/view questions, categories of questions and examination papers. The questions are divided in two types, multiple choice questions (including true/false) and long answer questions (essays). The teacher can create exams choosing the number of questions and the types of questions that exist in the pool of questions that are previously created. The selection is done randomly by the application and the teacher just determines the total number of both multiple choice or long answer questions as well as the importance (weight) of each one of them (including negative grades also). The student takes the random generated exam and receives his/hers grades. The grades of the multiple choice questions are done automatically, whereas for the long answer questions the teacher is responsible to put grades on. After the completion of the exam the teacher can view the student's final score via the control panel or a report.
\end{abstract}

Index Terms-Online examination system; Content Management; Wordpress plugin; Web Based Application; intelligent system; automated transaction

\section{INTRODUCTION}

In the recent years, as a result of the development of Internet technology, online examination systems have gained remarkable preference and acceptance in the education industry because they have modernized the process in which students prepare and appear for their examinations [1]. Also there has been a growing interest of light open source content management systems (CMS) such as WordPress or Drupal, that configured in an appropriate way, allow a teacher to set up quickly and easily an open environment for a virtual classroom/examination site.

\section{A. Content Management Systems}

A content management system (CMS) is a software that help us make websites easier, faster, browser compatible and responsive websites in a very short time with the powerful inbuilt features. The basic advantages of the most popular CMS are the following:

- Security

- Usability

- Documentation / Support

- Expansion and correction

- Easy administration / installation

\section{B. Wordpress}

Wordpress is a free and open source web software tool and a content management system (CMS) based on PHP and MySQL. It has many features including a plugin architecture and a template system. Wordpress is among the most popular systems in use on the Internet. Wordpress provides security and easy-to-use programming software both for developers and website administrators and there are thousands of developers who contribute to its source code optimization [2]. Plugins are tools which extend the functionality of Wordpress. The core of WordPress is designed to be clean, to maximize flexibility and minimize code bloat. Plugins offer custom functions and features so that each user can tailor their site to their specific needs [3], [4], [5]. The functions that provided by Wordpress are used in order the development to be done in its own environment. The application form is the plugin so both the installation/uninstallation can be done easily by the users. 


\section{Literature review}

In this section we examine the related works on the online examination systems. In education, the concept of E-Learning has grown rapidly from distance learning to virtual classrooms towards the online courses and online examinations. Universities and Colleges are trying to move from a paper-based to a paperless environment [1], [6], [7], [8], [9], [10], [11], [12], [13], [14], [15],[16],[17].

Many researchers proposed a number of online examination systems such as SIETTE [18], WETAS [19], EMS [20],WONES [21] and CBTS [22]. A number of application results using other open source programming languages such as PHP and MySQL can be found in [23], [24],[25],[26].

\section{ApPLiCATION DESCRIPTION}

Our proposed plugin application named (ODES) is developed for the Wordpress platform. Through this specific plugin the roles of the teacher and the student are created. The teacher inserts either multiple choice or long answer questions (essays) and can create exams. In each exam the teacher defines only the importance (weight/score) that each question will have (including negative values if needed).

The exam generation is based on a mixing of long answer and multiple choice questions which are selected in order to be displayed according the specification that entered by the teacher. The selection of the exam questions is done randomly. In the case of multiple choice questions, both questions and answers of each one are randomly displayed for different users. Multiple choice questions are automatically corrected by the system. On the other hand, there are long answer questions which are also displayed randomly for different users but the final score is given by the teacher himself.

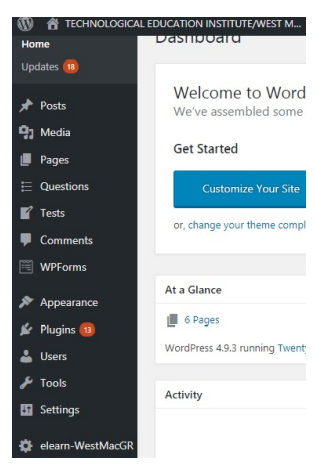

Fig. 1. Application options have been added in the menu

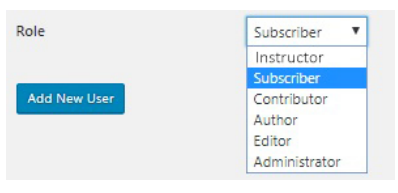

Fig. 2. Adding the Instructor user entity

By the time the exam is completed, the teacher is asked to check the long answer questions (if any) so as to give the grades for them. The final exam score(grades) appears automatically in the system for all students that take the exam with time stamp for each one of them.

\section{A. Plugin installation and activation}

Like most Wordpress functions, the plugin installation does not require any special knowledge on programming as the only thing that is required is the connection to the control panel and then the plugin is inserted (Plugins - $>$ Add new). In this case all the available plugins can be viewed and the selected one is loaded. The downloading procedure can be done with the use of any file transfer program. The uploading of plugin can take place in a zip form in the plugin's folder (/wp-content/plugins/) and it will be loaded automatically by Wordpress. Finally, the activation must be done manually.

Initially in the administration menu (Figure 11), there are three options the "Questions", "Tests" and "elearnWestMacGR".

- A new user entity can be created with the name "instructor" (Figure 2) that has administrator rights.

- In the database, a new table is added with the name wp_elearn_results in which the students' answers will be stored (see Figure 3).

\section{B. Application settings}

The application enables us to select in which page of our website we want all the exams to be displayed. From the popup menu we can select one of the pages that exist

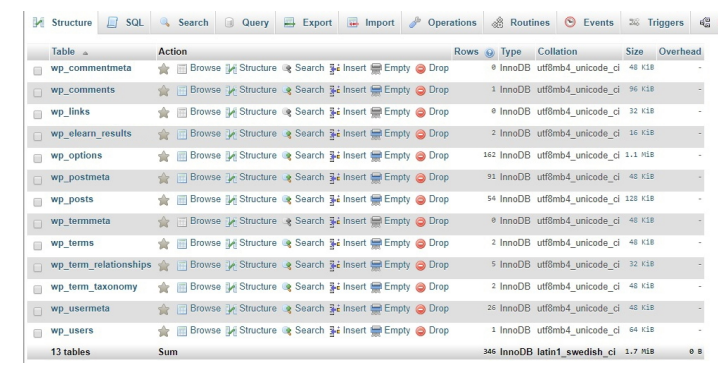

Fig. 3. The table wp_elearn_results of the database 


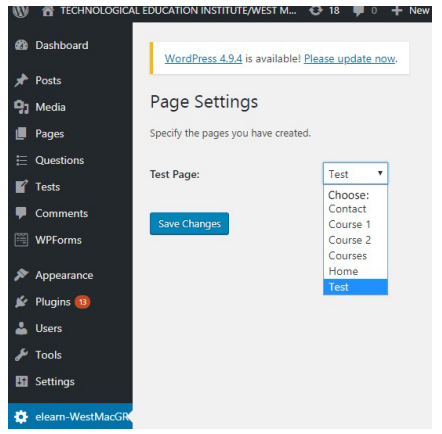

Fig. 4. Application settings

in the Wordpress and is defined as exam page (Figure (4).

The page settings can be found in file settings.php via Wordpress function add_menu_page

\section{Questions}

Questions are an custom post type which is defined in cpt-erotisi.php file by making use of register_post_type Wordpress function. Even though questions are posted they cannot be seen by anybody because during their definition the public setting is turned to false. They are only available through the control panel.

Every question belongs to one or more question categories that are also defined by cpt-erotisi.php file and it is a classification that is defined through register_taxonomy Wordpress function.

By pressing the menu "Questions" all the stored questions are displayed in a table where the "Title", "Type", "Category" and "entry date" of each question are viewed (Figure 5).

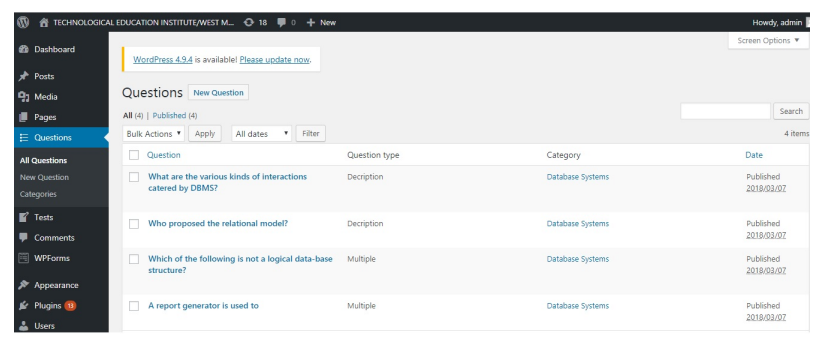

Fig. 5. Custom post type questions

1) Question adding: In order to add a new question we need to select the submenu "New Question". Then a form will be displayed for completion (Figure 6). This form is almost the same with the standard form that

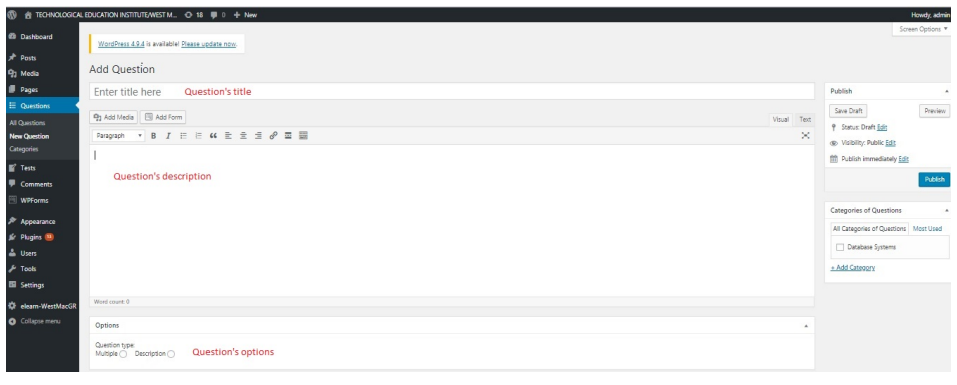

Fig. 6. New question adding

exists in the Wordpress in order to post an article or a page.

In the form there are the following fields :

- Title

- Question description

- Question options

- Categories

- Publication

In the Title field we complete the main question that the student must answer.

In the Description field the general instructions of the question are optional. This field can accept formatted text as well as multimedia files (images, video, etc.).

In the Categories field (Figure 7) we can select in which of the existed categories or

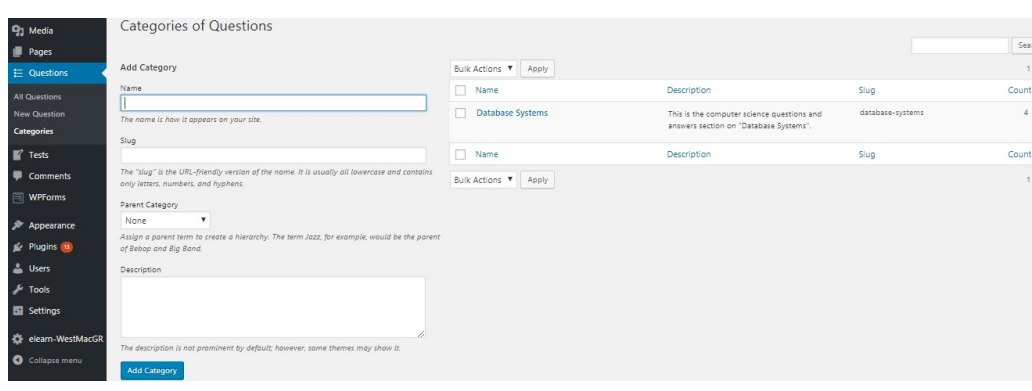

Fig. 7. Question category adding

sub-categories the question belongs. In the case we want to add a new category we must press the link "+ Add category". In the first field we enter the title of the category, in the popup menu - parent category - we select if the category will be a sub-category or not and we press the button "Add category"as in Figure 8

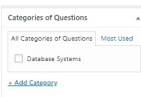

Fig. 8. Quick question category add 


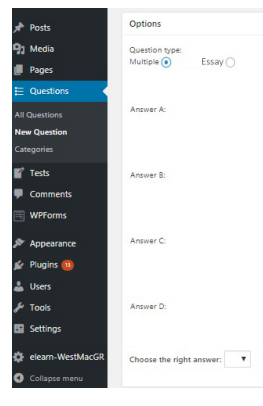

Fig. 9. Multiple choice questions options

In the "Publish" field we can publish the question or store it in order to change its settings later.

Finally, in the "Options" field we define several question elements that unlock depending on the type of question that we want to add.

2) Question options: Initially in the "Option" field we' re required to select if the question is multiple choice or long answer. If we select "Description" then some necessary extra options are displayed automatically. The swapping is done via jQuery code dynamically.

As shown in Figure 9, if we select multiple choice questions in the "Question type" we have to define the four possible answers and then which one is the correct. Finally, we can store or publish the question.

3) Possible Errors during publication: In case the question publication takes place without having chosen its type, then the system warns us as shown in Figure 10.

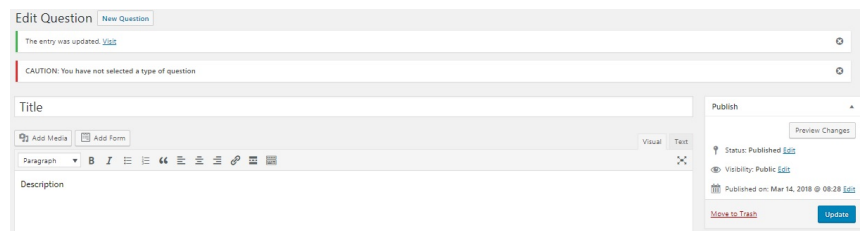

Fig. 10. Warning for not choosing question type

4) Question categories: In the third sub-menu of the menu "Questions", there is the question category management page (Figure 11). We can see all added categories and from the left page side we can add new ones. Also, we can edit each category separately (Figure 12).

\section{Exams}

Exams are, like questions, an adapted post type and are defined in the cpt-diagonisma.php file. They are accessible to administrator/teacher user group in contrast with the questions and have their own properties.

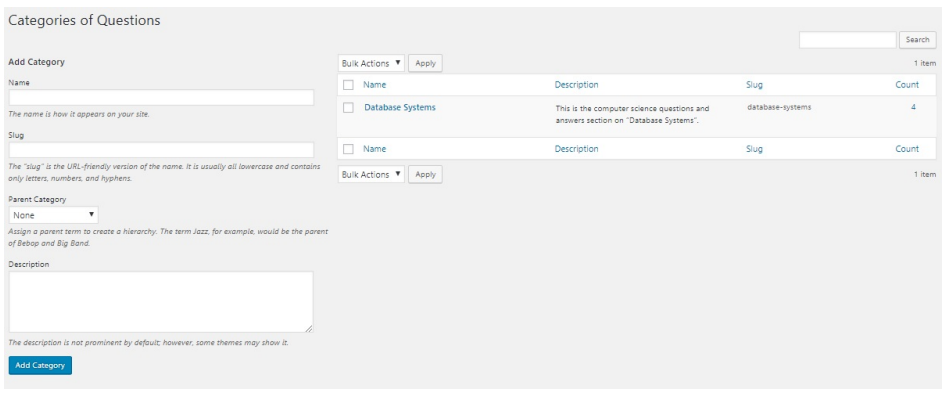

Fig. 11. Management question category page

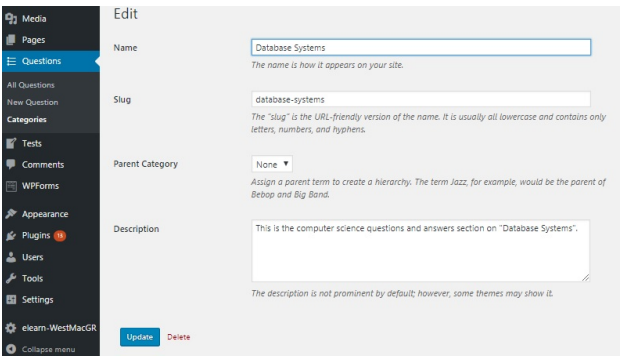

Fig. 12. Question category editing

By pressing the menu "Tests" all the stored exams are displayed in a table where the Title and Entry date are viewed. Furthermore, the sub-menus "All Tests", "New Test" are viewed as well (Figure 13).

1) Adding Exams: In order to add a new exam we just need to press the sub-menu "New test"(Figure 14).

In the new exam page the following fields can be completed:

- Title

- Permanent link (it is displayed after the draft save)

- Description

- Options

- Publish

In the Title field we complete the title that we want the exam to have

In the field Permanent link we can define which the unique URL is going to be. The options are also depended on the Wordpress permanent link settings.

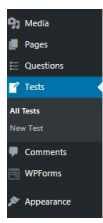
Tests
An:(2)
Euk
$\square$
$\square$
$\square$
$\square$
$\square$

Fig. 13. Custom post type exam 


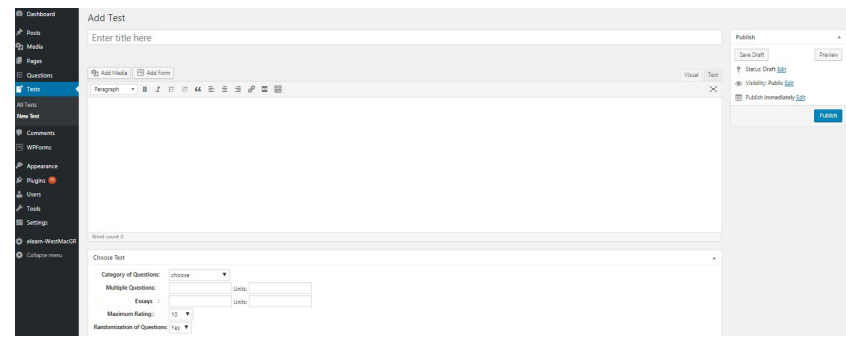

Fig. 14. New exam addition

In the Description field we can write general instructions concerning the exam. This field can accept formatted text as well as multimedia (images, video, etc.). This field can be blank.

In the Publish field we can publish or save the exam as a draft and edit it later without being published yet.

Finally, in the Options field there are options concerning how the exam is going to manage the questions.

2) Exam options: Initially in the exam options the teacher defines from which question category the selection will take place. In the popup menu all the existing categories are displayed automatically. Then we complete how many multiple choice and long answer questions will be selected. Next to each selection there are the corresponded question importance fields (Figure 15). The importance is about the question type and there

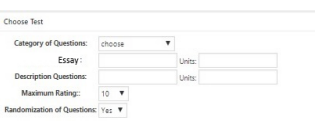

Fig. 15. Exam options

is an equivalent allocation on each one of them. Then, reduction to the unit by the system is done and the scoring will be displayed with a maximum of 10 or 100 depending on what we have chosen on the popup menu "Maximum Rating". Finally, we select if there will be a question randomization. If "No" is selected then the system will display the same questions in the same order to every student.

3) Running the Student exam: As shown in the following question, depending on the options that were previously made we can see all the available exams. The exam page is defined in the templates/pagediagonismata.php file.

By pressing on one of the exams (Figure 16) the student is redirected to his/her their exam page which is defined by tempates/single-diagonisma.php file.

Initially the student is asked to provide his personal details. But the system has already selected the questions

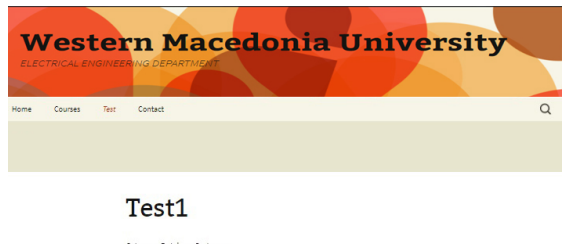

Test (Database Systems)

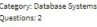

Fig. 16. Exam page

which will be displayed in him and will store them along with his personal details. This happens because we don't want the student to view the selected questions and to prevent him from making any unwanted actions (e.g. to close the browser tab and revisit the exam hoping for "easier" questions).

Test1status:

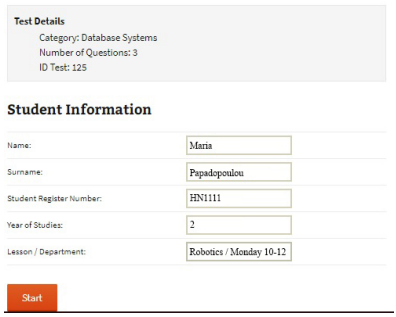

Fig. 17. Registering student details for the exam

When the user presses the exam "Start" button his/her personal details are stored in the database and specifically in the the wp_elearn_results table (Figure 17). The entry time, exam status and selected questions are also stored in a array in order to be stored in a table field. Furthermore, the HTML symbol " "' has been override by putting the "Y" symbol. This technique prevents any unwanted malicious action.

Then the student is redirected in a new web page that has all the questions that have been selected randomly and is asked to answer them (Figures 18 19). In the case of multiple choice questions the possible answer order is random as well.

The student, after reading and answer the questions must press the "Finalize" button in order the exam to be stored in the database and then the teacher will be able to check it (Figure 20p.

Before the final answers is sent, there is a final validation message (Figure 21) warning the student that 


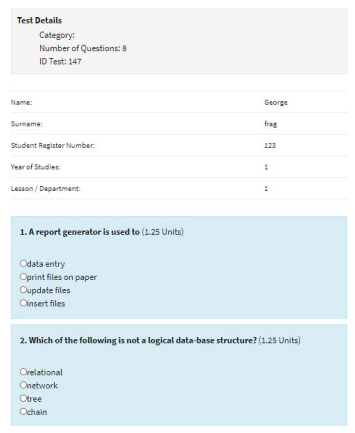

Fig. 18. Multiple choice questions

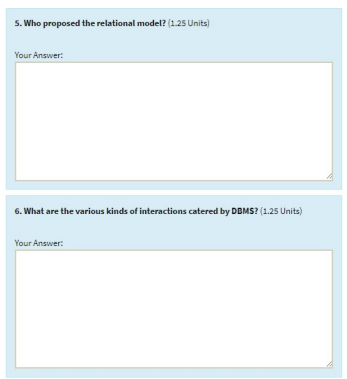

Fig. 19. Long answer/essay form question

he/she cannot be able to change the answers if the exam is submitted.

The answers have been stored in the database and also the status has been changed from "open" to "finalized"(Figure 22).

\section{E. Answer correction by the teacher}

The teacher can view the stored answers from the menu "elearn-WestMacGR" $\rightarrow$ "Tests". In the templates/admin-results.php file, there is a table with all the answered exams. In the table the exam title, students' personal details, exam status, grades and entry date are shown. By pressing the exam title, the teacher can correct and put grades on.

As shown in Figure 23, in the templates/adminresults.php file the submitted answers have already been

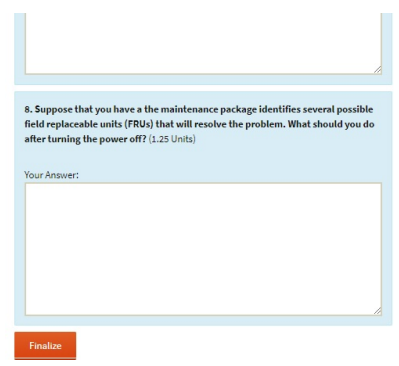

Fig. 20. Finalize button

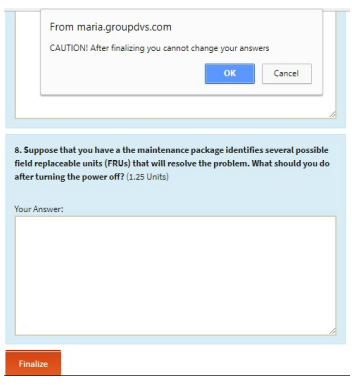

Fig. 21. Warning message before test submmited
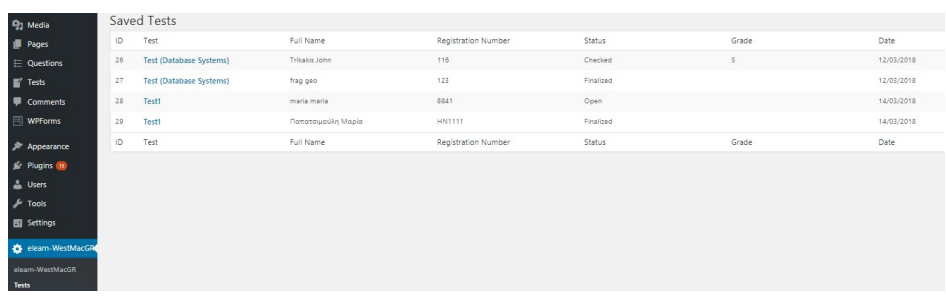

Fig. 22. Status change from open to finalized

corrected and the teacher is asked to check the long answer questions.

After the teacher inserts the grade in the long answer questions in the list with the stored exams the grade is displayed for the specific exam and the status changes to "Checked"(Figure 24).

In Figure 25 the admin can see all the stored exams using phpMyAdmin application.

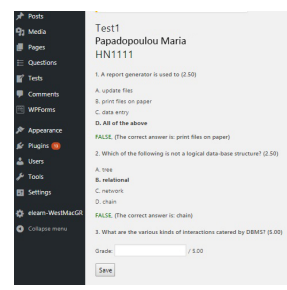

Fig. 23. Exam check and score finalization

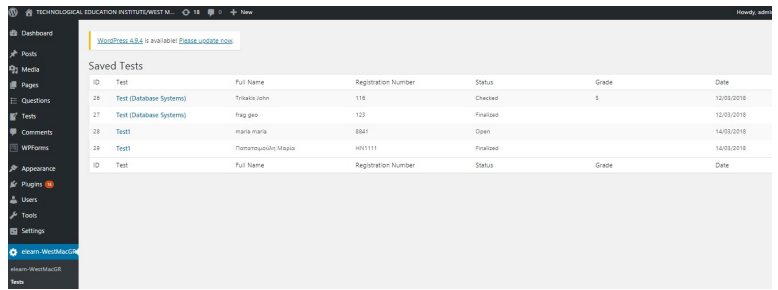

Fig. 24. Final Grades display 


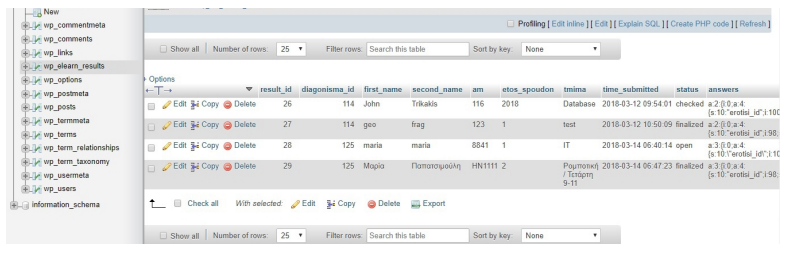

Fig. 25. Stored exams management

\section{WORDPRESS PLUGIN TABLE ARCHITECTURE}

As it shown in Figure 26, the table of the plugin is named wp_elearn_results. In this table are saved the test results of the students

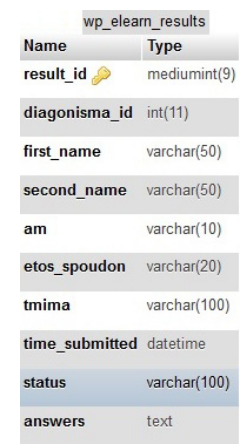

Fig. 26. Plugin's table in which the results of student's tests are stored

The following fields are displayed in the table:

Result_id: The primary key of the result table. (Type: Integer, with a maximum length of 9 digits)

-Diagonisma_id: A field in which are stored the identifiers of the tests. (Type: integer, with a maximum length of 11 digits)

-First_name: A field in which is stored student's name. (Type: Varchar, with a maximum length of 50 digits)

-Second_name: A field in which is stored the last name of the student. (Type: Varchar, with a maximum length of 50 digits)

-Am: A field in which is stored student's identifier. (Type: Varchar, with a maximum length of 10 digits)

-Etos_Spoudon: A field in which is stored the year of the studies of the student. (Type: Varchar, with a maximum length of 20 digits)

-Tmima: A field in which is stored the department of studies of the student. (Type: Varchar, with a maximum length of 100 digits)

-Time_submitted: A field in which is stored the date and the time of the completed test. (Type: Date and time with the following form YYYY-MM-DD HH:MM:SS)
-Status: A filed in which is stored test's status which can be Open, Checked or Finalized. (Type: Varchar, with the maximum length of 100 digits)

-Answers: A field in which are stored the answers of the test. (Type: Text, with a maximum length of 65535 digits)

\section{FUNCTIONAL AND NON-FUNCTIONAL ANALYSIS}

\section{Functional :}

The system supports three different user groups:

- The students have the ability to participate in exams

- The Teachers have the ability:

- add/edit/delete/view questions and categories of questions

- add/edit/delete/view exams

- evaluate exams (Grades)

- keep an attendance log for each of their tests

- mark a student as a successful participant

- edit their profile

- The Administrator has the ability:

- all the abilities of Teacher user group plus editing the teachers' profile

\section{Non-Functional:}

- There is no need for installing additional software as the environment works with web browsers so it is accessible from anywhere with any operating system.

- security and reliability issues.

\section{CONCLUSiOns}

In the present paper a plugin application (ODES) is developed for the Wordpress platform that manages the examination and auto-grading for students exams and supports conducting exams, collects the answers, auto mark the submissions, and produce the reports for the test and meet the needs of several levels of education (Primary,Secondary,Tertiary etc.) developed with open source software tools and taking into account their advantages and features. In future editions of the ODES application we plan to add the following features:

- Link mail to the users and the ability to send notification emails to a single email address, multiple email addresses or a group of WordPress users.

- Show answers at the end of the test or immediately after selection.

- Export/Import results to CSV file.

- add multimedia files (images, videos etc.) and other types of questions as well. 


\section{REFERENCES}

[1] M. I. Younis and M. S. Hussein, "Construction of an online examination system with resumption and randomization capabilities," International Journal of Computing Academic Research (IJCAR), vol. 4, no. 2, pp. 62-82, 2015.

[2] S. Fernandes and A. Vidyasagar, "Digital marketing and wordpress," Indian Journal of Science and Technology, vol. 8, no. S4, pp. 61-68, 2015.

[3] T. Koskinen, P. Ihantola, and V. Karavirta, "Quality of wordpress plug-ins: an overview of security and user ratings," in Privacy, Security, Risk and Trust (PASSAT), 2012 International Conference on and 2012 International Confernece on Social Computing (SocialCom). IEEE, 2012, pp. 834-837.

[4] B. Williams, O. Richard, and J. Tadlock, Professional WordPress Plugin Development. Wrox Press Ltd., 2011.

[5] M. Hills, "Navigating the wordpress plugin landscape," in Program Comprehension (ICPC), 2016 IEEE 24th International Conference on. IEEE, 2016, pp. 1-10.

[6] M. J. Rosenberg and R. Foshay, "E-learning: Strategies for delivering knowledge in the digital age," Performance Improvement, vol. 41, no. 5, pp. 50-51, 2002.

[7] M. Driscoll, "Blended learning: Lets get beyond the hype," $E$ learning, vol. 1, no. 4, pp. 1-4, 2002.

[8] E. T. Welsh, C. R. Wanberg, K. G. Brown, and M. J. Simmering, "E-learning: emerging uses, empirical results and future directions," international Journal of Training and Development, vol. 7, no. 4, pp. 245-258, 2003.

[9] D. R. Garrison, E-learning in the 21st century: A framework for research and practice. Taylor \& Francis, 2011.

[10] P.-C. Sun, R. J. Tsai, G. Finger, Y.-Y. Chen, and D. Yeh, "What drives a successful e-learning? an empirical investigation of the critical factors influencing learner satisfaction," Computers \& education, vol. 50, no. 4, pp. 1183-1202, 2008.

[11] D. Zhang, J. L. Zhao, L. Zhou, and J. F. Nunamaker Jr, "Can e-learning replace classroom learning?" Communications of the ACM, vol. 47, no. 5, pp. 75-79, 2004.

[12] D. Tavangarian, M. E. Leypold, K. Nölting, M. Röser, and D. Voigt, "Is e-learning the solution for individual learning?", Electronic Journal of E-learning, vol. 2, no. 2, pp. 273-280, 2004.

[13] S. Hrastinski, "Asynchronous and synchronous e-learning," Educause quarterly, vol. 31, no. 4, pp. 51-55, 2008.

[14] Y. Levy and M. M. Ramim, "The e-learning skills gap study: Initial results of skills desired for persistence and success in online engineering and computing courses," in Proceeding of the Chais 2017 Conference on Innovative and Learning Technologies Research, 2017, pp. 57-68.

[15] H. Al-Samarraie, B. K. Teng, A. I. Alzahrani, and N. Alalwan, "E-learning continuance satisfaction in higher education: a unified perspective from instructors and students," Studies in Higher Education, pp. 1-17, 2017.

[16] J. Shen, S. R. Hiltz, and M. Bieber, "Collaborative online examinations: Impacts on interaction, learning, and student satisfaction," IEEE Transactions on Systems, Man, and CyberneticsPart A: Systems and Humans, vol. 36, no. 6, pp. 1045-1053, 2006.

[17] A. Trivedi, "A relevant online examination system," in Technology for Education (T4E), 2010 International Conference on. IEEE, 2010, pp. 32-35.

[18] E. Guzmán and R. Conejo, "Self-assessment in a feasible, adaptive web-based testing system," IEEE transactions on Education, vol. 48, no. 4, pp. 688-695, 2005.
[19] K. Henke, "Web-based test, examination and assessment system," in Proc. 9th IASTED Int. Conference on Computers and Advanced Technology in Education (CATE), Lima-Peru, 2006, pp. 321-326.

[20] M. Z. Rashad, M. S. Kandil, A. E. Hassan, and M. A. Zaher, "An arabic web-based exam management system," International Journal of Electrical \& Computer Sciences IJECS-IJENS, vol. 10, no. 01, pp. 48-55, 2010.

[21] R. Sheshadri, T. C. Reddy, and N. A. Kumar, "Web-basedsecure online non-choice-based examination system (wones) using cryptography," Journal of Discrete Mathematical Sciences and Cryptography, vol. 15, no. 6, pp. 353-368, 2012.

[22] T. M. Fagbola, A. A. Adigun, and A. O. Oke, "Computer-based test (cbt) system for university academic enterprise examination," International journal of scientific \& technology research, vol. 2, no. 8, pp. 336-342, 2013.

[23] I. Skordas, G. Fragulis, and A. Triantafyllou, "e-AirQuality: A dynamic web based application for evaluating the air quality index for the city of kozani, hellas," in Informatics (PCI), $201115^{\text {th }}$ Panhellenic Conference on. IEEE, sep 2011, pp. 171-174. [Online]. Available: http://ieeexplore.ieee.org/stamp/ stamp.jsp?arnumber=6065046

[24] I. Skordas, G. F. Fragulis, and A. G. Triantafyllou, "A.Q.M.E.I.S.: Air quality meteorological and enviromental information system in western macedonia, hellas," in 1st International Conference on Buildings Energy Efficiency and Renewable Energy Sources 2014, Kozani, Greece, 2014.

[25] L. Lazaridis, M. Papatsimouli, and G. F. Fragulis, "S.A.T.E.P.: Synchronous-asynchronous tele-education platform," in Proceedings of the SouthEast European Design Automation, Computer Engineering, Computer Networks and Social Media Conference, ser. SEEDA-CECNSM '16. New York, NY, USA: ACM, 2016, pp. 92-97. [Online]. Available: http://doi.acm.org/10.1145/2984393.2984395

[26] I. A. Skordas, N. Tsirekas, N. Kolovos, G. F. Fragulis, A. G. Triantafyllou, and M. G. Bouliou, "e-Sem: Dynamic seminar management system for primary, secondary and tertiary education," in 2017 South Eastern European Design Automation, Computer Engineering, Computer Networks and Social Media Conference (SEEDA-CECNSM), Sept 2017, pp. 1-4. 